\title{
TEODOSIO I SIGUE SIENDO TEODOSIO I ${ }^{1}$
}

\author{
POR
}

\author{
JAVIER ARCE \\ CSIC. Universitat Rovira i Virgili, Tarragona
}

\section{RESUMEN}

El presente artículo trata de demostrar que la reciente propuesta de J. Meischner sobre el missorium de Teodosio de la Real Academia de la Historia de Madrid, en el sentido de que se trata de un objeto representando no a Teodosio I (identificación tradicional) sino a Teodosio II, y que por tanto es un producto de la Corte de Rávena del año 421, es insostenible e indemostrable. La propuesta de J. Meischner no resuelve los diversos problemas que plantean todos los elementos iconográficos, epigráficos, históricos y de contexto que presenta el missorium. Antes al contrario, no encuentra sólida explicación científica al hecho de que el missorium recordaba las decennalia del emperador lo que necesariamente sólo puede corresponder a las de Teodosio I celebradas el año 388. Si hubieran sido las de Teodosio II, se daría el caso de que se estarían celebrando 10 años después de que éstas se hubiesen celebrado efectivamente, como atestigua la Chronica de Marcelino. Una serie de observaciones de tipo iconográfico y de tipo histórico complementan y fundamentan la teoría de que el missorium de Teodosio I sigue siendo de Teodosio I.

\section{SUMMARY}

The present article tries to demostrate that the recent suggestion made by J. Meischner about the missorium of Theodosius from de Royal Academy of History in Madrid, in the sense that it is an object representing not Theodosius I (traditional identification) but Theodosius II, and therefore, a product from the Court of Ravenna, made in the year 421 , is unnaceptable and unconvincing. The new proposal does not solve the different problems raised by the iconographic, epigraphic, and historical context of the object. One of them, and the most important, is the mention in the missorium of the decennalia of the emperor, that should correspond necessarially to the one celebrated for Theodosius I in the year 388 and not for Theodosius II. Should be this the case then, the inscription will celebrate 10 years later, the decennalia that we know for certain that took place in the year 411 as attested in the Chronica of Marcellinus. Some other observations, historical and iconographical, assure that the traditional identification of Theodosius I in the missorium, should be mantained. Theodosius the first continues being Theodosius I.

' Quiero agradecer especialmente a G. Lambert sus amables indicaciones, así como al prof. I. Wood por su disponibilidad ante mis preguntas y discusiones. Del mismo modo, debo agradecer a Dña. Nuria Ruiz por haber pasado al ordenador un manuscrito difícil. Por fin, quiero expresar mi agradecimiento al prof. M. Almagro Gorbea, de la Real Academia de la Historia, por haberme proporcionado las magníficas fotografías del missorium que reflejan su estado actual completamente restaurado.
El reciente trabajo de Jutta Meischner sobre el missorium de Teodosio, que se encuentra en el Museo de la Real Academia de la Historia de Madrid, en el que propone que se trata de un objeto que representa no a Teodosio I (379-395 d. C.), sino a Teodosio II (402-450 d. C.), pone en duda y cuestiona una larguísima y prestigiosísima tradición de investigadores que lo han identificado hasta ahora con el primero, desde R. Delbrueck hasta A. Grabar, desde J. Beckwith hasta H. Peirce y R. Tyler, desde académicos como A. Delgado y A. García y Bellido, J. M. ${ }^{a}$ de Navascués o A. Blanco Freijeiro, hasta historiadores, arqueólogos, filólogos o numísmatas (J. Matthews, A. Cameron, S. MacCormack, H. Schlunk, B. Kiilerich, y un larguísimo elenco) ${ }^{2}$. Nunca, que yo sepa, desde su descubrimiento en 1847, en Almendralejo (provincia de Badajoz), en las cercanías de la antigua colonia de Augusta Emerita, se ha puesto en duda la identificación con Teodosio I, ni su fecha (en torno al año 388, con algunas oscilaciones, de acuerdo con la inscripción que bordea el missorium y que menciona las decennalia del emperador $\left.{ }^{3}\right)$. Sí, sin embargo, se ha estado en desacuerdo en la identificación de las figuras que flanquean al emperador $y$, en cuanto a otros detalles

${ }^{2}$ El artículo de Jutta Meischner, Das Missorium des Theodosius in Madrid, JdAI, 111, 1996, p. 389-432 (=JM Missorium). Para la bibliografía detallada ver B. Kiilerich, Late Fourth Century Classicism in the Plastic Arts, Odense Univ. Press, 1993, p. 19-26 y mis indicaciones en J. Arce, El missorium de Teodosio I: Precisiones y Observaciones, $A E s$ $p A, 49,1976$, p. 119-139; ver también las sugestivas reflexiones de S. G. MacCormack, Art and Ceremony in Late Antiquity, Univ. California Press, 1981, p. 214-221; así como las de J. Matthews, Western Aristocracies and Imperial Court (A. D. 364-425), Oxford, 1975, p. 112-113; M. Hendy, Aspects of Coin Production and Fiscal Administration in the Late Roman and Early Byzantine Period, $N C, 7$ th ser. XII, 1972, p. 117-139; el libro de R. Delmaire, Largesses sacrées et res privata, EFR, 121, Rome, 1989, p. 471-494 resulta fundamental para comprender la producción de estos objetos en el contexto de la corte imperial; ver, del mismo modo, $P$. Bastien, Monnaie et Donativa au Bas-Empire, Wetteren, Belgique, 1988 (esp. p. 29).

DN THEODOSIU PERPET AVG OB DIEM FELICISSIMUM X. Para anteriores lecturas equivocadas de la inscripción ver J. Arce, AEspA, 49, 1976, p. 123. Ejemplos de otros objetos semejantes con celebración de decennalia o vicennalia en Delmaire, cit. (n. 1), p. 473-474. 


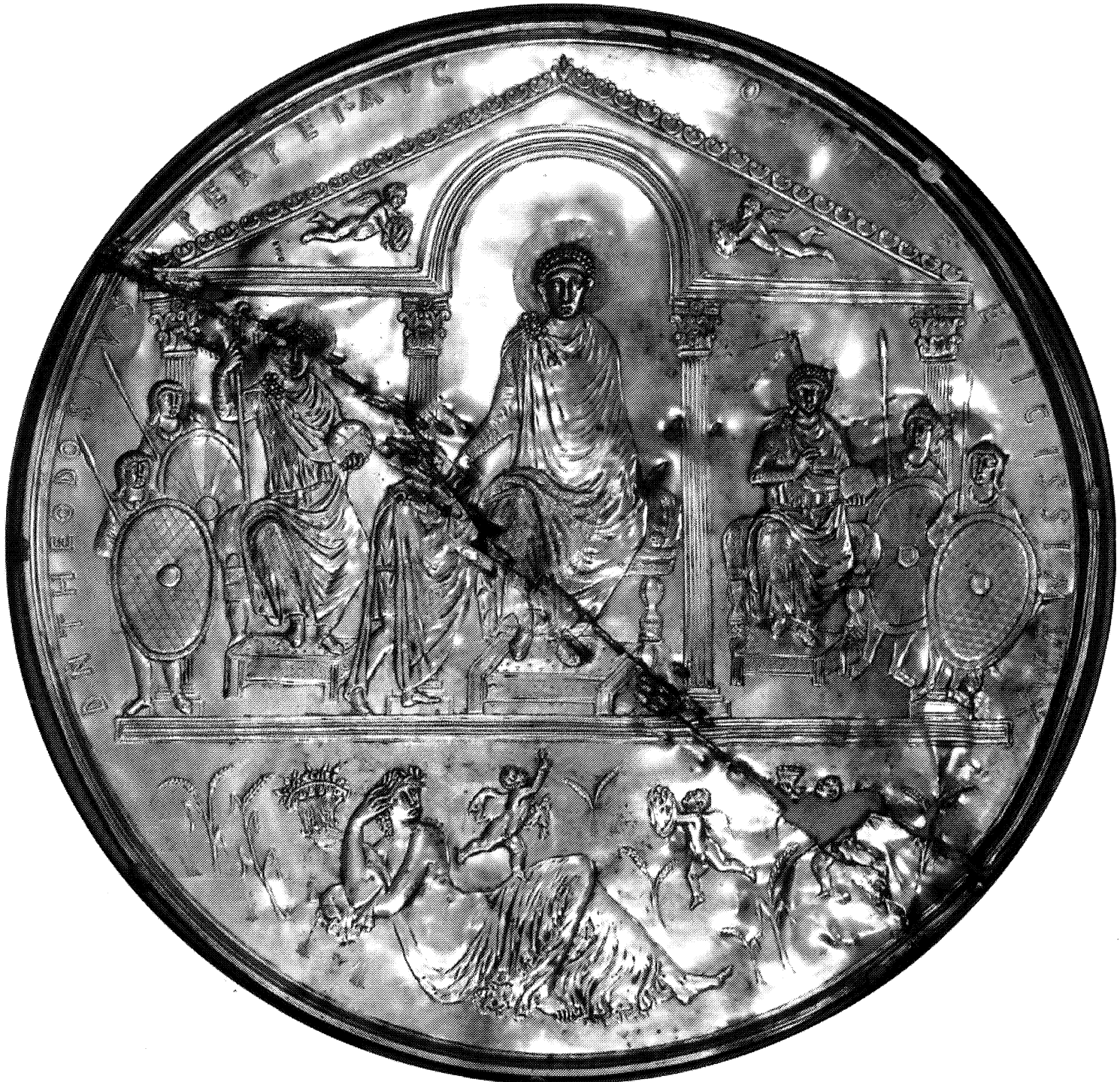

Fig. 1.-El missorium de Teodosio I. Museo de la Real Academia de la Historia. Cortesía del Museo de la Real Academia de la Historia.

iconográficos, a su significado y a la razón de su presencia $^{4}$.

Con esta propuesta la Sra. Meischner no hace otra cosa que estimular la investigación y poner en duda una tradición adquirida, como ocurre en tantos otros casos: en el día de hoy, por ejemplo, la identificación del Mausoleo de Centcelles (Tarragona) como tumba del emperador Constante (337-350 d.

4 Sobre la discusión referida a la identificación de los personajes representados y a las figuras alegóricas cfr. Arce, cit. (n. 1), p. 122-132; Kiilerich, cit. (n. 1), p. 22-24
C.), propuesta por los arqueólogos alemanes ${ }^{5}$, está muy seriamente puesta en entredicho y gana cada día más credibilidad la tesis de que se trata de una villa privada con unos mosaicos que representan en la cúpula al dominus y a la domina o quizá a un obispo ${ }^{6}$. Nadie cree hoy ya tampoco que la famosa

${ }_{5}^{5}$ H. Schlunk, Die Mosaikkuppel von Centcelles, MB, Bd. 13, Madrid, 1988 (con notas y comentario de A. Arbeiter).

6 J. Arce, Constantinopla, Tarraco y Centcelles, Butlletí Arqueològic, 1996, p. 147-165; R. Warland, Status und Formular in Repräsentation des spätantiken Führungeschicht, $R M, 101,1994$, p. 175 ss. 
cabeza procedente de Mulva (Munigua) sea Hispania, sino una Venus o una divinidad femenina ${ }^{7}$. Los ejemplos sobre nuevas interpretaciones, afortunadamente, se pueden multiplicar y son bien conocidos por los especialistas. Ello quiere decir, simplemente, que la ciencia progresa y que es gracias a la revisión, a la investigación y a la discusión por lo que se avanza, aunque existan todavía quienes, demostrando escasa categoría científica, respondan airados, malhumorados y contrariados cuando se les critica o se les proponen nuevas alternativas.

Hace unos años, el prof. J. Ch. Balty publicaba un artículo en el homenaje a H. Jucker, en el que ponía en duda la identificación del famoso busto de oro de Aventicum con el emperador Marco Aurelio, proponiendo que se trataba de un retrato del emperador Juliano. M. Jucker, campeón de la identificación con Marco Aurelio, respondió con un largo trabajo que llevaba el significativo título de «Marc Aurel bleibt Marc Aurel», en el que intentaba neutralizar los argumentos de Balty con determinación y convicción ${ }^{8}$. Yo no soy ningún campeón de la causa teodosiana pero, al emprender ahora el presente estudio, confío en que al final mis argumentos sean lo suficientemente sólidos y convincentes como para poder seguir diciendo que «Theodosius (I) bleibt Theodosius (I)» en el missorium de Madrid, simplemente porque los argumentos de J. Meischner proponiendo a Teodosio II, no me resultan ni convincentes ni suficientes, siendo en cambio forzados y especulativos.

\section{EL MISSORIUM DE TEODOSIO: INTERPRETACIÓN Y ESTADO} DE LA CUESTIÓN

La interpretación del missorium de Teodosio, de su función y cronología, destinatario y lugar de producción, y de su significado, es un problema que no se resuelve solamente con la eventual identificación del personaje central representado, sino que implica el hallar una explicación coherente para todos los componentes de una escena y de sus elementos ad-

7 W. Grünhagen, Ein Frauenkopf aus Munigua, Pantheon, 19, 1961, p. 53-59; T. Hauschild, Munigua. Ausgrabungen an der Stützmauer des Forums, 1985, $M M, 27,1986$, p. $325-$ 343; J. Arce, La iconografía de «Hispania» en época romana, AEspA, 53, 1980. p. 77-94; W. Trillmich et alii, Hispania Antiqua. Denkmäler der Römerzeit, Mainz, 1993, p. 387; J. Arce-S. Ensoli-E. La Rocca (a cura di), Hispania Romana. Da terra di conquista a Provincia dell'impero, Roma, 1997, p. 412, n. ${ }^{\circ} 222$.

8 J. Ch. Balty, Le prétendu Marc-Aurèle d'Avenches, Eikones. Festchrift H. Jucker, 12 Beiheft, Antike Kunst, Bern, 1980, p. 57-63; H. Jucker, Marc Aurel bleibt Marc Aurel, Bulletin de l'Association pro Aventico, 26, 1981, p. 5-36. yacentes (como es, por ejemplo, la inscripción), ya que ellos constituyen un todo, un conjunto, una escena, que fue creada con una intencionalidad identificativa y narrativa precisa y concreta. Consiguientemente, es casi superfluo recordar e insistir en que el missorium y su escena poseen un contexto histórico preciso, factor éste, el contexto histórico, fundamental y clave para la interpretación del objeto. Producción y destinatario, lugar de producción y lugar de hallazgo final son, igualmente, elementos básicos para entenderlo y para explicar su recorrido final.

Digo esto, porque las páginas que siguen tratarán de enfrentarse primordialmente a là contestación de estas preguntas y a estos temas; y porque creo que es imprescindible advertir que el problema del missorium no es (ni puede ser) un problema artístico exclusivamente. Considerar que las características estilísticas pueden ir por un lado y que el significado y la interpretación histórica pueden ir por otro, es metodológicamente incorrecto e inapropiado. Las características estilísticas fluctúan en el tiempo. Se copian, se retardan (o adelantan), sufren vicisitudes diversas que impiden el uso de criterios rígidos que, por otro lado, en ningún modo pueden alterar la coherencia histórica que rodea la manufactura de un objeto de estas características. Los criterios estilísticos y los paralelismos resultan en el fondo inasequibles y aleatorios. Los contextos históricos son de mayor credibilidad, precisamente porque explican motivos y causas, porque dan razón a la explicación de la emergencia de un lenguaje y no de otro. Si las consideraciones estilísticas (muy subjetivas siempre), o los paralelismos formales (todavía más subjetivos) fuerzan o quebrantan la coherencia histórica, creo que prevalece o debe prevalecer esta última ${ }^{9}$.

${ }^{9}$ Es bien conocida la gran variabilidad de criterios para fijar cronologías e identificaciones entre los especialistas. El Juliano de Thasos (Lévêque) es ahora Antoniniano (Fittschen); el coloso de Barletta ha sido identificado con Constantino, Valentiniano I, Marciano, Honorio, Justiniano I, León: cfr. Kiilerich, cit. (n. 1) p. 236-237. Sobre el tema conviene recordar una frase de A. M. Clarke: «la identificación de retratos romanos importantes es un viejo y quizás inofensivo deporte. Es incurablemente acientífico y si ha alcanzado importancia en las épocas de la arqueología científica no es porque los arqueólogos sean premeditadamente tontos sino porque así hay más material más fácil para comparar» (citado en C. Vermeule, AJA, 63, 1959, p. 108 y en J. et J. Chr. Balty, BIBegRom 44, 1974, p. 23). La incertidumbre y la arbitrariedad para la fijación de cronologías o identificación de retratos de emperadores del s. III ha sido brillantemente expuesta por R. McMullen, Roman Goverment's Response to Crisis, YUP, 1976, p. 16 ss.; cfr. también J. Arce, Sobre el supuesto Balbino de Itálica: una nota, $A E \operatorname{sp} A, 49$, 1976, p. $195-196$ 
Teniendo en cuenta estas premisas, me parece importante considerar en primer lugar las consecuencias que lleva consigo la identificación de $\mathrm{J}$. Meischner con Teodosio II en el missorium. Desde el punto de vista histórico son importantes, pero, adelantémoslo ya, resultan, cuando menos, excesivamente forzadas e imaginativas.

La investigación sobre el missorium ha establecido, siempre considerando que la identificación y la cronología corresponden a Teodosio I, lo siguiente:

1.-El missorium es un producto elaborado en los talleres de los argentarii dependientes del comes sacrarum largitionum, producido en Tesalónica o en Constantinopla ${ }^{10}$.

2.-Fue enviado como regalo/largitio del emperador al vicarius Hispaniarum, residente en las cercanías de la capital de la Diocesis Hispaniarum, Augusta Emerita. Dicho alto funcionario se encuentra representado en el missorium en el acto de recibir de manos del emperador mismo los codicilli de su nueva función ${ }^{11}$

3.-El emperador Teodosio se representa en el centro, sentado en la sella curulis $^{12}$, flanqueado por Valentiniano II, con cetro y globus, y por Arcadio, hijo mayor de Teodosio, llamado a ser el heredero ${ }^{13}$. La escena celebra el nombramiento del funcionario y las decennalia del emperador, tal y como se recuerda en la inscripción del borde del missorium, decennalia que corresponderían al año $387 / 388^{14}$.

4.- - Teodosio aprovecha la ocasión para enviar un mensaje claro y rotundo de su supremacía en el gobierno del Imperio, situándose indebidamente en el centro de la escena, rodeado de candidati de origen bárbaro con un fondo ideal de palatium, delante del cual, sentado en el tribunal y acompañado de sus colegas en el Imperio, sanciona con su presencia la delegación de poderes representada. El emperador se muestra en toda su potencia y majestad, al tiempo que acentúa sus virtudes y los efectos de su gobierno: los felicia tempora para toda la Tierra (por ello, aparecen en el registro inferior represen-

\footnotetext{
10 Delmaire (cit. n. 1); Matthews (cit. n. 1); Hendy (cit. n. 1); Arce, p. 133; Kiilerich (cit. n. 1).

J. Arce (cit. n. 1) con la discusión; Kiilerich (cit. n. 1) p. 22. La Sra. Kiilerich prefiere identificarlo con un P. Praetorio Orientis: ¿Cynegius?

12 No es un trono: el mejor paralelo es la ilustración del Calendario de Philocalo representando a Constancio II: cf. M. R. Salzman, On Roman Time, UCal Press, 1990. p. 34, y especialmente: H. Stern, Le Calendrier de 354, Paris, 1953, p. 152 y ss.

13 Discusión en Arce (cit. n. 1) p. 123 ss.; y en Kiilerich (cit. n . 1) p. 22.

4 D. Kienast, Römische Kaiesertabelle, Darmstadt,1996, p. 339: celebradas en Tesalónica. Kiilerich (cit. n. 1) p. 26; J. Arce (cit. n. 1) p. 121-122.
}

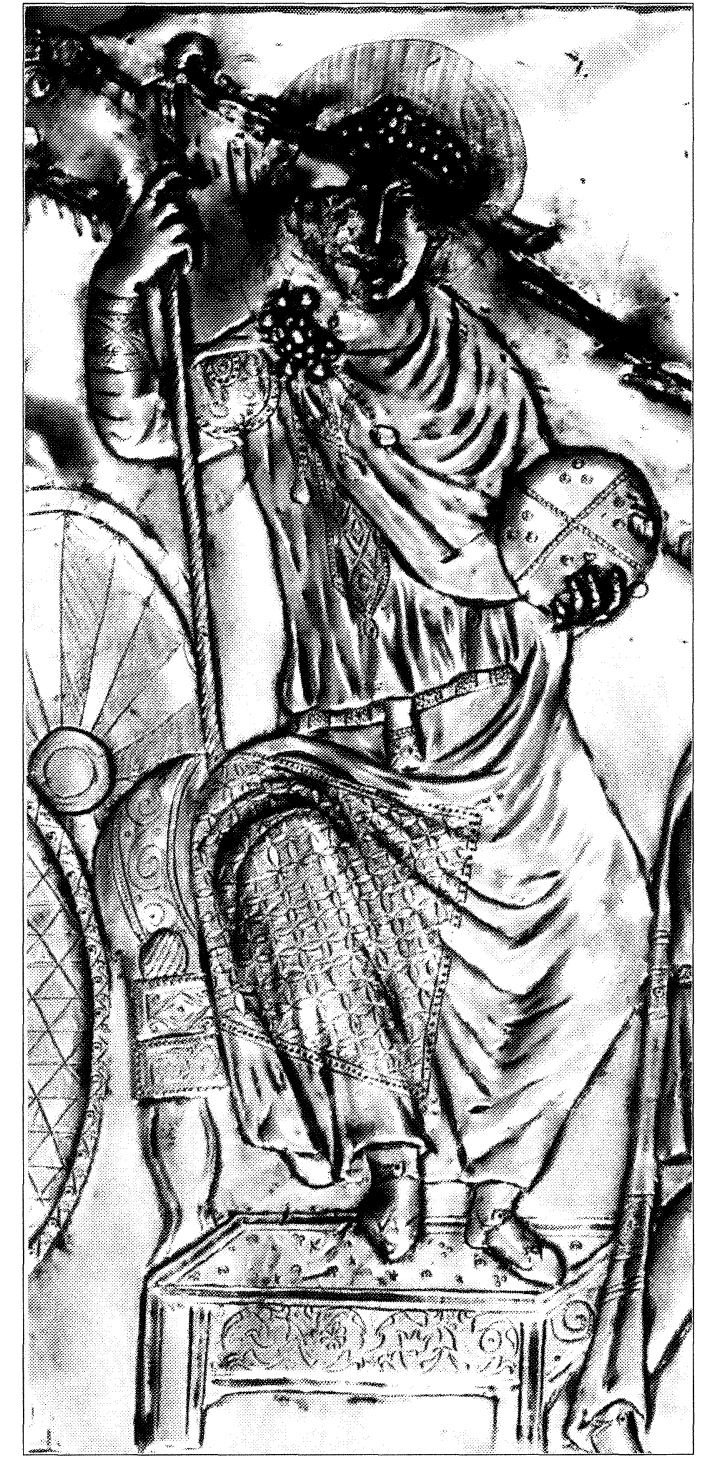

Fig. 2.-Valentiniano II en el missorium de Teodosio. Sentado en la sella curulis se representa con el cetro (hasta summa imperii) y el globus. Cortesía Museo de la Real Academia de la Historia.

tados Tellus y Karpoi, como si se tratase del exergo de una moneda conmemorativa) ${ }^{15}$.

5.-Este mensaje es todavía más fuerte y más claro porque Teodosio se sitúa indebidamente en el centro, como tutor y como protector de sus dos acompañantes, uno de ellos efectivo emperador $s e$ nior (aunque no en edad) de la Pars occidentis, Valentiniano II, quien, precisamente por ello, es el único de la escena que lleva el resumen de todos los

15 Arce (cit. n. 1) p. 128-130; Kiilerich (cit. n. 1) p. 23-24 


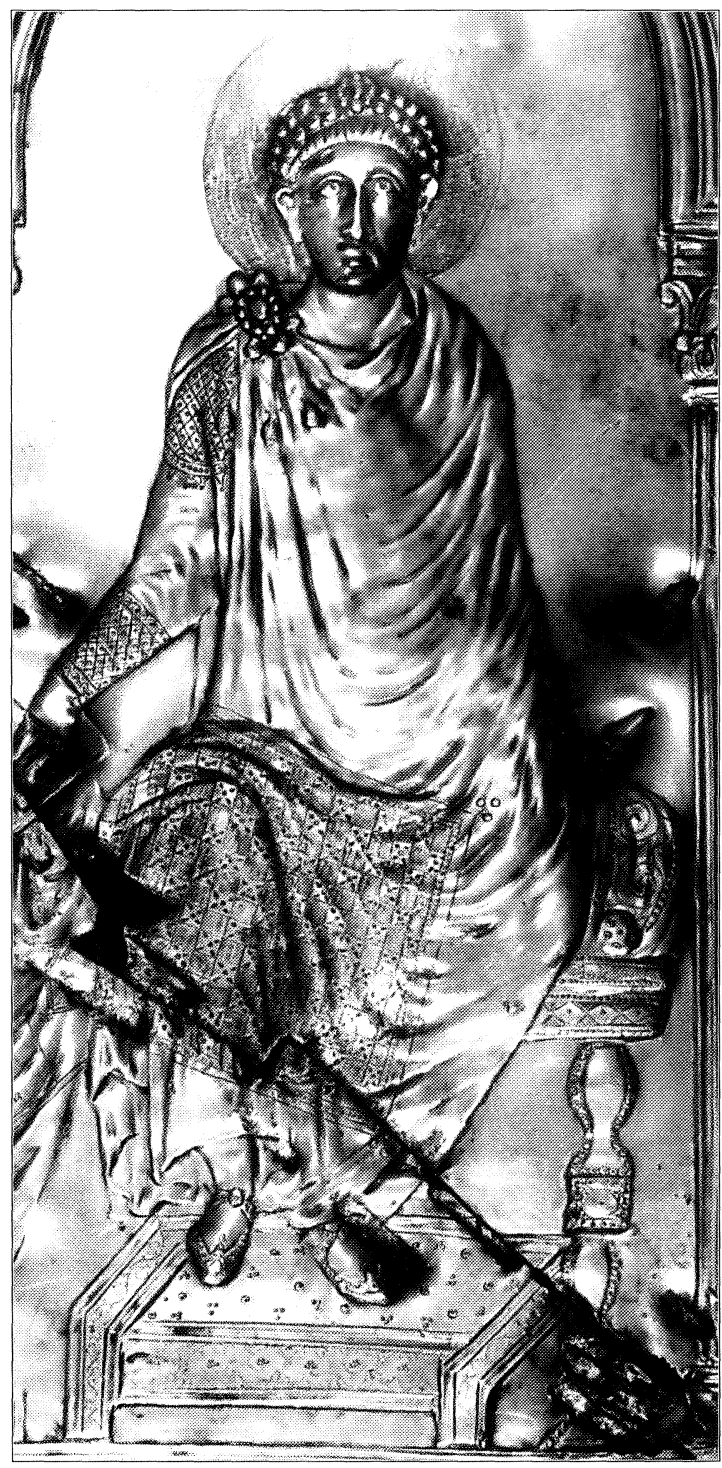

Fig. 3.-Teodosio en el missorium de la Real Academia de la Historia. Sentado en la sella curulis y apoyando sus pies en el subpedaneum, entrega con su mano derecha el liber mandatorum o los codicilli a un funcionario, representado mucho menor, como signo de inferioridad ante la majestad y sanctitas imperial. Cortesía del Museo de la Real Academia de la Historia.

ornamentos del poder: cetro, hasta summa imperii, globus, toga picta, diadema ${ }^{16}$.

6.-Esta «usurpación» del poder por parte de Teodosio, perfectamente reflejada en el missorium, está constatada igualmente en monedas y legislación contemporáneas, en las que el emperador Teo-

16 A. Alföldi, Hasta-summa imperii. The spear as embodiment of Sovereignty in Rome, AJA, 63, 1959, p. 1 ss; id. Die monarchische Repräsentation im römische Kaiserreiche, Darmstadt, 1970.

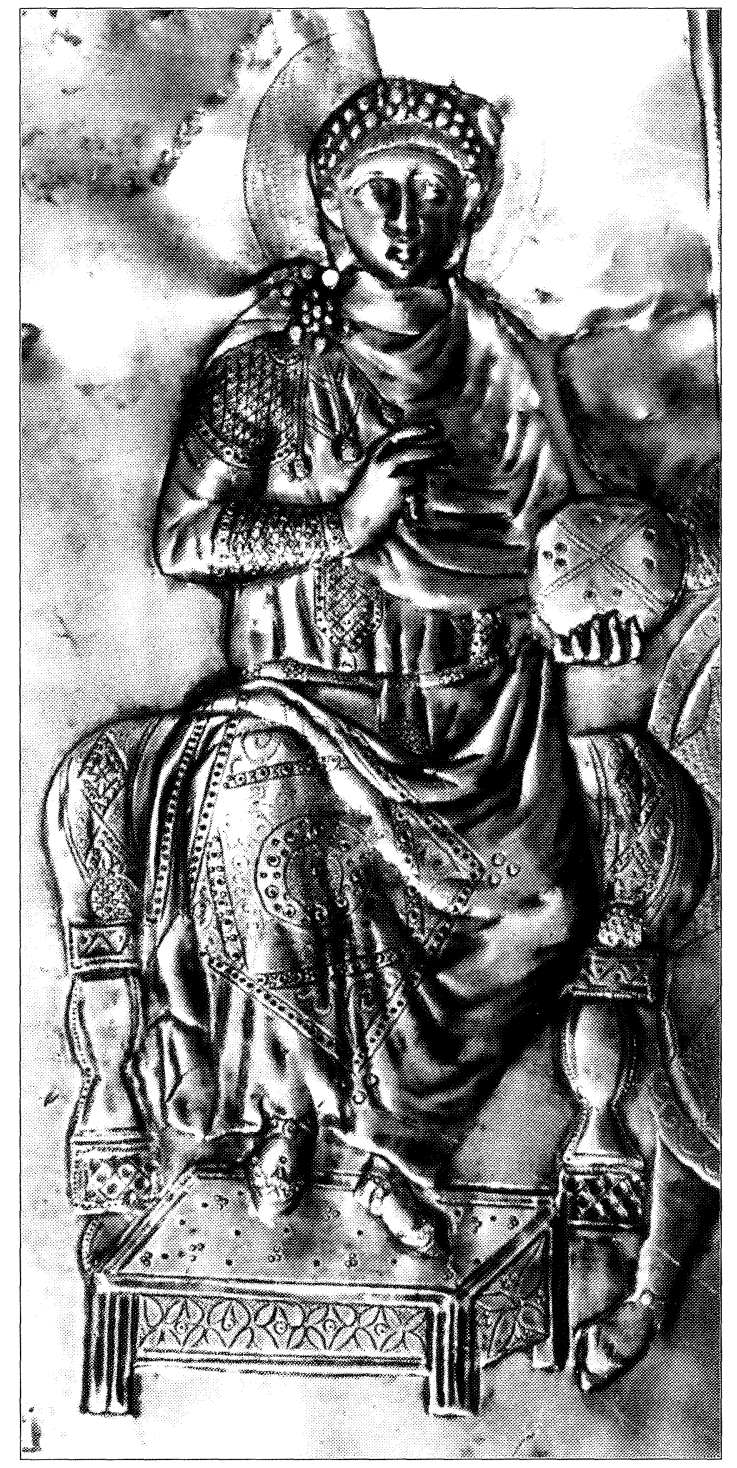

Fig. 4.-Arcadio en el missorium de Teodosio. Se representa sentado en la sella curulis en el acto de hablar y con globus. Cortesía del Museo de la Real Academia de la Historia.

dosio se muestra siempre preeminente, ya que Valentiniano II fue siempre «un emperador sin tierras», un emperador ficticio (como lo definió A. Piganiol ${ }^{17}$ ). Recientemente S. MacCormack ha insistido sobre ello: "The missorium, then, does not observe a ceremonial correctness, but portrays a de facto state of affairs» ${ }^{18}$.

7.-La presencia de «bárbaros» en el missorium (que no aparecen con anterioridad más que en una

17 A. Piganiol. L'Empire Chrétien, Paris, 1972 (ed. Chastagnol), p. 269; Arce (cit. n. 1) p. 123-125 (monedas).

18 S. MacComarck (cit. n. 1) p. 216. 
ocasión, en el missorium de Constancio II y poco después en la base del obelisco de Teodosio en Constantinopla ${ }^{19}$ ) encuentra su justificación y explicación en el texto de Temistio (dirigido a Teodosio) en el que le indica que el buen emperador no es sólo el que acepta y se ocupa de los romanos sino también de los bárbaros, el que es capaz de reconocer a todos los hombres, el philanthropos ${ }^{20}$.

8.-El missorium no contiene ningún signo ni alusión al cristianismo, como podría esperarse de un imperator christianissimus que había comenzado ya su legislación contra los paganos. Ello no es de extrañar si se tiene en cuenta el lenguaje ambiguo de la iconografía de la Corte en la que lo que se muestra es una escena burocrática y administrativa ${ }^{21}$

9.-La presencia de un objeto de tan excepcional calidad y valor ( $15 \mathrm{~kg}$ de plata ${ }^{22}$ ) en las cercanías de Augusta Emerita en Hispania encuentra una explicación perfecta en época teodosiana, sobre todo si tenemos presente la importancia del funcionariado teodosiano en la Diocesis Hispaniarum (Teodosio mismo era natione spanus) y el hecho de que el objeto se haya encontrado cerca de la capital ${ }^{23}$.

Estas son las conclusiones a las que ha llegado la investigación sobre el missorium hasta el momento, después de muchas y diversas matizaciones, precisiones, observaciones y reflexiones. Ellas constituyen un discurso analítico en el que todos los elementos se complementan y encuentran una alta probabilidad de coherencia interpretativa, realizada desde los más diversos puntos de vista: arqueológico, artístico, histórico, filológico, numismático.

Pero este discurso coherente y explicativo salta por los aires ante la nueva propuesta de J. Meischner: el missorium sería un producto de la corte de Honorio en Rávena realizado a instigación de Gala Placidia Augusta, para Teodosio II, emperador de la Pars orientis, a fin de que aceptase el orden dinástico establecido por Honorio en el 421 (vid. infra). Esta propuesta, como es lógico y legítimo reclamar, requiere para ser aceptada, al menos, una explicación igualmente coherente. Por lo tanto, si la nueva propuesta ha de ser aceptada habría que explicar:

1) La identificación y presencia de los personajes representados.

19 Sobre la base del obelisco de Teodosio cfr. ahora Kiilerich (cit. n. 1) p. 31-49.

${ }_{20}$ S. MacComack (cit. n. 1) p. 217; Themistius, or. 15

21 Arce (cit. n. 1) p. 134; Kiilerich (cit. n. 1) p. 26

${ }^{22}$ Kiilerich (cit. n. 1) p. 19

${ }^{23}$ Natione Spanus: Hydatius, Chr. 2 (a. 379) (Burgess) Augusta Emerita: J. Arce, Mérida tardorromana (284-409 d. C.), Hom. Sáenz de Buruaga, Badajoz, 1982, p. 209-226. Ver también G. Bravo, Prosopographia theodosiana (I): en torno al Ilamado «clan hispano», Gerión, 14, 1996, p. 381-398.
2) Justificar su presencia en términos de la observancia del ceremonial romano tardío y los símbolos de poder que cada uno detenta, cetro, globus, etc.

3) Encontrar una explicación satisfactoria a la leyenda que alude a las decennalia.

4) Justificar o, al menos, intentar explicar el por qué el objeto ha sido hallado en las cercanías de Augusta Emerita en la nueva cronología que se le asigna (a partir del 421 al menos).

5) Demostrar de forma indiscutible que estilísticamente el objeto no puede ser anterior al 421 .

\section{LA NUEVA PROPUESTA}

La nueva propuesta de J. Meischner es que el missorium de la Real Academia de la Historia de Madrid es un producto diseñado y creado por la corte de Honorio en Rávena para hacer contentar, aceptar y propagar la nueva política de nombramientos dinásticos del emperador occidental, realizada en el 421 , a fin de que Teodosio II reconociese su validez y legitimidad ${ }^{24}$. El missorium es, o sería, así un objeto enviado al emperador y a los gobernadores provinciales («Wiederholungen») con una finalidad diplomática, y en el que se representan: a) Honorio (emperador occidental con cetro y globus), representado a la izquierda del espectador; b) Teodosio II, en el centro, preeminente; c) Valentiniano III, hijo de Gala Placidia y del Augusto Constancio III, investido por Honorio como co-regente en febrero del 421; d) el propio Constancio III, que sería el pequeño y subordinado personaje que recibe la confirmación y sanción de su cargo o investidura imperial, de parte de Teodosio II. Este «documento propagandístico y diplomático», emanado de la propia corte de Rávena, que había creado independientemente una serie de nombramientos corregentes de Honorio y/o destinados a gobernar en el futuro (Valentiniano III), pero que no habían sido aceptados por Teodosio II, estaría destinado a satisfacer las aspiraciones dinásticas de Gala Placidia, esposa del recién nombrado Augusto Constancio III y madre del pequeño Valentiniano III (que contaba en este momento con sólo dos años, aunque ostentaba ya el título de nobilissimus) ${ }^{25}$. El missorium presentaba así a Teodosio II la «constelación imperial» que debía reconocer y aceptar. Dado que éste no aceptó los nombramientos de su tío en Occidente, el missorium es (o sería, según J. Meischner) un producto posterior a la muerte de

${ }^{24}$ J. M., Missorium, p. 418 ss.
25 Olympiodoro: frag. 33 . 
Constancio III, pero en el que implícitamente se reconocía a posteriori su nombramiento como Augusto en el acto de la escena central ${ }^{26}$.

El missorium celebraba también las decennalia de Teodosio con retraso; pero ello sería debido a que se ofrecía así un signo más del intento conciliador. A esta propuesta ha llegado J. Meischner a través sobre todo del análisis estilístico, que le hace pensar que el missorium no puede ser un producto de los años 380/390, sino posterior ${ }^{27}$.

En resumen; las consecuencias de esta interpretación son que el emperador Honorio aceptó enviar un missorium (o varios) a Teodosio II y a los gobernadores o prefectos del Pretorio, en el que él mismo se representaba en segundo plano (aunque con las insignias del poder), y daba toda la importancia central a Teodosio II, que aceptaba póstumamente a Constancio III como Augusto, representado casi insignificante delante del emperador oriental. Honorio incluía en la representación también a Valentiniano III, para que se supiese que Teodosio II aceptaba también su nombramiento como nobilissimus. Honorio, además, celebraba para Teodosio II las decennalia retrasadas, en el 421 . De por qué apareció este objeto en las cercanías de Augusta Emerita no se nos dice nada, ni tampoco de la indicación de su peso en el reverso expresado en letras griegas.

Llegados a este punto, y sin entrar todavía en los argumentos estilísticos, conviene recordar los detalles históricos que rodean el problema central del año 421 que es, según Jutta Meischner, el año de producción precisa del missorium.

\section{EL AÑO 421}

El contexto histórico en el que fue creado el missorium de Madrid, si se acepta la nueva propuesta, aunque se encuentra ya tratado por J. Meischner, requiere un nuevo examen a la luz de la lectura de las fuentes antiguas, a las que la autora no hace ninguna mención, aunque toma su información de la bibliografía moderna sobre el tema. Por otro lado, algunos textos fundamentales, al parecer, le han pasado desapercibidos, como es el referente a las decennalia de Teodosio II que más adelante comentaremos.

Después del matrimonio del patricio Constancio (III) con Gala Placidia, impulsado por el emperador Honorio ${ }^{28}$ y consumado en enero del $417^{29}$, y des-

${ }^{26}$ J. M., Missorium, p. 419-420.

27 J. M., Missorium, p. 390-415 (estilo).

28 J. M., Missorium, p. 422; ver también K. Holum, Theodosian Empresses, Berkeley, 1982.

29 Hydacio, Chr: 62

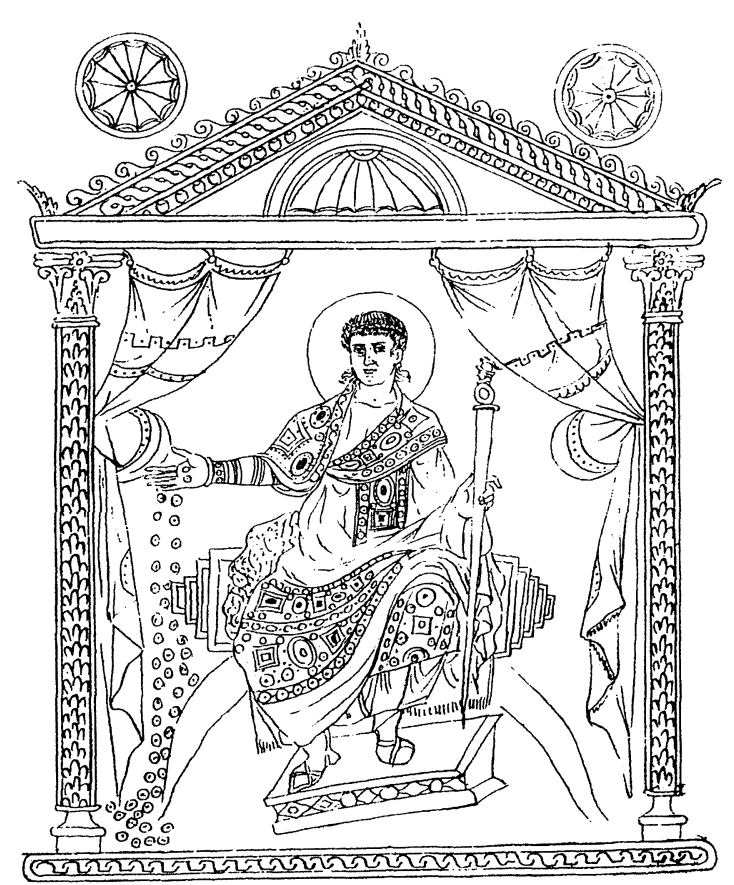

Fig. 5.-Ilustración del calendario del año 354 representando al emperador senior Constancio II, teniendo en la mano izquierda el cetro, y con la derecha, derramando monedas en el acto del donativum. Copia de Peiresc. Biblioteca Vaticana.

pués del nacimiento de sus dos hijos (Honoria y Valentiniano III) ${ }^{30}$, en la Corte de Rávena se hacía patente el irresistible ascenso, prestigio e influencia de Constancio, que tantos problemas, sobre todo militares, había resuelto al emperador ${ }^{31}$. El momento decisivo y preparatorio para la culminación de la carrera y ambiciones del omnipotente patricio fue su consulado (III), compartido nada menos que con Teodosio II en el año $420^{32}$.

Tan alta dignidad preparó el terreno para su designación como co-augusto con Honorio en febrero del año siguiente, $421^{33}$. Este nombramiento lo hizo Honorio con desgana ${ }^{34} \mathrm{y}$, por tanto, quizá presionado por Placidia o por el propio Constancio y «sin respetar las relaciones familiares» ${ }^{35}$, es decir, alterando sorprendentemente el sistema dinástico normal o esperado. El nombramiento de Constancio III como co-augusto de Honorio no poseyó la intencionalidad

\footnotetext{
${ }^{30}$ Olympiodoro, frag. 33.

31 Ver PLRE, II, F1. Constantius 17. En general: K. Holum, Theodosian Empresses, Berkeley, 1982; V. A. Sirago, Galla Placidia e la trasformazione politica dell'occidente, Louvain, 1961; S. I. Oost, Galla Placidia Augusta, ChicagoLondon, 1968.

${ }_{32}$ Consulado conjunto: PLRE, l. $c$.

${ }^{33}$ Co-augusto: PLRE, II Iulius Constantius 17.

${ }^{34}$ Olympiodoro, frag. 33.

35 Philostorgio, 12.12.
} 
de derrocar al emperador oriental, sino la de reforzar la pars occidentis con un general capaz de controlar los territorios perdidos y ya en manos de pueblos bárbaros o usurpadores. Pero, ciertamente, causó preocupación en Constantinopla, hasta el punto de que Teodosio no quiso reconocer el nombramiento: la proclamación fue enviada a Teodosio, pero no fue aceptada ${ }^{36}$; se enviaron eikones de Constancio a Oriente, pero Teodosio no los aceptó ${ }^{37}$. Sólo el rechazo de su nombramiento movió a Constancio a preparar una expedición militar contra Teodosio a fin de ser reconocido ${ }^{38}$. La prematura muerte del antiguo patricio en septiembre del 421 tranquilizó los ánimos y Valentiniano III, nobilissimus a sus dos años de edad, ya podía ser reconocido, como de hecho así ocurrió poco después ${ }^{39}$, lo que quiere decir que el único obstáculo para el reconocimiento del sistema sucesorio establecido por Honorio había sido Constancio III quien, al fin y al cabo, era un extraño en la familia ${ }^{40}$.

La nueva propuesta sobre el missorium sitúa su concepción y difusión justamente en ese mọmento crucial posterior a la muerte de Constancio III, a fin de que sirviese de vehículo propagandístico para las aspiraciones de la familia reinante (Honorio, Teodosio, Valentiniano), pero situando a Teodosio por encima de todos; y a fin de que Teodosio reconociera póstumamente el nombramiento de Constancio III, representado también en el missorium en el acto de recibir la confirmación.

Ahora bien, esta suposición implicaría que Rávena proponía una representación de la jerarquía imperial a Constantinopla situándose en inferioridad y sin consulta previa a Teodosio II. Es impensable que Honorio hubiese consentido esto porque, en la norma seguida por las representaciones tardorromanas, ambos emperadores aparecen igualmente investidos de sus respectivos poderes, excepto en el caso de que uno de ellos sea césar ${ }^{41}$. Es impensable también que diseño y decisión sobre el missorium hayan sido exclusivamente iniciativa de Gala Placidia porque, aunque era Augusta, no tenía ningún poder en la producción de estos missoria ${ }^{42}$ y, si se hubiese saltado las normas, su situación hubiera sido muy comprometida con Honorio. Es, también, sumamente

\footnotetext{
36 Olympiodoro, frag. 33.

37 Philostorgio, 12.12

38 Ver conjuntamente Olympiodoro y Philostorgio

${ }^{39}$ Natalis Valentinianus purpurae: CIL, I, 275.

40) Olympiodoro, frag. 46; Philostorgio 12.12.

${ }^{41}$ Como ocurre con tanta frecuencia en las series numismáticas: cfr. A. Grabar, L'Empereur dans l'art Byzantine, Strasbourg, 1936, p. 26 ss.; RIC, IX, Londinium 26 (Máximo usurpador y Teodosio)

${ }^{42}$ R. Delmaire (cit. n. 1) p. 471 ss
}

improbable que los recipendiarios del missorium entendieran o identificaran a Constancio III en el pequeño personaje que se encuentra representado en una tal situación de inferioridad.

Sobre la intervención de Gala Placidia en programas iconográficos se suele citar, y J. Meischner hace referencia a ello, la noticia de Agnellus sobre los mosaicos que ésta mandó hacer en la basílica de San Juan Evangelista en Rávena ${ }^{43}$. Allí estaban representados, en torno a ella y a sus hijos (Valentiniano III y Honoria), la pareja reinante (Teodosio II y Eudocia), los emperadores ligados por lazos familiares (Graciano, Valentiniano II, Teodosio I, Arcadio, Eudocia) y también Constantino el Grande y Constancio II ${ }^{44}$. Pero este programa iconográfico, realizado como consecuencia de un voto, no es parangonable con la propuesta que hace J. Meischner para el missorium. En primer lugar, no sabemos cuándo se realizaron estos mosaicos ${ }^{45}$; en segundo lugar, la ausencia de Constancio III resultaría significativa; y, por fin, todo el conjunto es un «curieux amalgame où sont intentionnellement confondues succession et parenté» ${ }^{46}$.

La lectura del missorium de acuerdo con la nueva propuesta resulta, como se ve, excesivamente forzada, inverosímil y demasiado imaginativa, además de que presupone demasiadas hipótesis que no encuentran fundamento objetivo en la documentación ${ }^{47}$

Pero aún suponiendo que esta interpretación fuera correcta o posible, encuentra dificultades y obstáculos insalvables y definitivos para ser aceptada. Es el primero de ellos el de la inscripción.

\section{LAS DECENNALIA}

Este missorium propagandístico de la familia de Honorio, que pretendía el reconocimiento de Teodosio II, celebraba también las decennalia del emperador: D N THEODOSIVS PERPET AVG OB DIEM FELICISSIMVM $\mathrm{X}$.

J. Meischner reconoce que en el año 421 no era posible celebrar las decennalia de Teodosio II porque éstas «debían haberse celebrado o en el 412 o

${ }^{43}$ Agnellus, Liber Pontificalis Ecclesiae Ravennatis, MGH, SRLong. p. 307; Grabar, L'Empereur, p. 28-29; G. Dagron, Empereur et prêtre, Paris, 1996, p. 46.

44 Dagron, ibm. p. 46.

45 A. Cameron, The Empress and the Poet: Paganism and Politics at the Court of Theodosius II, YClS, 27, 1982, $217-$ 289, que habla del 437 !

46 Dagron (cit. n. 42 ), p. 46

${ }^{47}$ Como el palacio del fondo: J. M., Missorium, p. 430. Pero ver mi propuesta en op. cit. (n. 1) p. 131-132. 
en el 418», ya que Teodosio II fue nombrado Augusto en el 402, aunque lo fue efectivo a la muerte de su padre Arcadio en el $408^{48}$. Sin embargo, para obviar esta dificultad, señala que no siempre las decennalia se celebraban con rigor y exactitud matemáticas y pone varios ejemplos de ello ${ }^{49}$. Por lo tanto, el missorium celebraría las decennalia retrasadas en cuatro años o en diez años, según se considere válida la fecha de elevación el 402 o el 408.

Ahora bien, esto supondría que la corte de Honorio difundió un missorium/mensaje celebrando retrasadas las decennalia del emperador oriental; y, además, lo emitió como consecuencia y para celebrar las mismas (ob felicissimum ... ), lo que está en contradicción con la teoría mantenida por la autora sobre las razones y causas del missorium.

Pero aún hay más y más grave. Sabemos por varias fuentes que Teodosio II sí celebró las decennalia con precisión y exactitud en el año $411^{50}$ : la Chronica del comes Marcelino señala en la entrada correspondiente al año 411: Theodosius Junior decennalia, Honorius Romae vicennalia dedit ${ }^{51}$. Por si ello fuera poco, la evidencia numismática así lo corrobora: en el 411 Teodosio II acuñó en Constantinopla solidi que celebraban simultáneamente sus decennalia y las de Honorio ${ }^{52}$. El anverso de una de las emisiones lleva el busto de Honorio y, en el reverso, Constantinopla sentada en un trono con cetro y escudo ${ }^{53}$. Resulta que el único co-regente en el año 411 de Teodosio II era Honorio ${ }^{54}$. Por mucho que queramos retrasar la celebración de las decennalia, es impensable que se celebrasen como tales en el momento en que Teodosio II iba a cumplir sus vicennalia, y es inaceptable también pensar en un error de este calibre, además de que se trataría de repetir una celebración que ya había tenido lugar efectivamente diez años antes.

Éste es quizá el principal obstáculo para aceptar la nueva propuesta sobre el missorium de Teodosio. Por el contrario, hemos visto que, en el caso de que se trate de Teodosio I, no existe ninguna contradic-

\footnotetext{
48 Muerte de Arcadio: PLRE, I, Arcadius.

49 J. M., Missorium, p. 425-426; pero ver las conclusiones d A. Chastagnol, BSN Antiquaires de France, 1984, p. 106.

${ }^{50}$ Chastagnol, ibm., p. 106.

51 Chronica de Marcelino, s.a., 411 (Chr. Min. II). La Chronica refiere meticulosamente la cadencia: 422, 430, etc.

52 W. E. Kaegi, Byzantium and the Decline of Rome, Princeton, 1968, p. 16 ss.

${ }_{53}$ R. Boyce, A New Solidus of Theodosius II and other vota Solidi of the Period, Festal and Dated Coins of the Roman Empire, Four Papers, NUM, n. ${ }^{\circ} 153$, Nueva York, 1965 , p. $43-45$.

${ }^{54}$ Kiilerich (cit. n. 1) p. 19, n. 42; Chastagnol (cit. n. 48) p. 106.
}

ción ni dificultad para interpretar coherentemente ni la inscripción ni la iconografía.

\section{OTROS ASPECTOS}

La tradición iconográfica de la representación del emperador acompañado por sus colegas, nimbado, rodeado de candidati, que se continúa en el missorium de Teodosio, no es propia ni de Rávena ni de la época de Honorio (años 410/430). Por el contrario, nace al menos en época tetrárquica, con modelos muy claros por ejemplo en las pinturas del $s a$ crarium del culto imperial de Luksor, con la representación de Diocleciano y Maximiano Herculeo ${ }^{55}$. Se continúa en ejemplares monetarios, solidi, sobre todo de época constantiniana o de Juliano ${ }^{56}$, y halla un perfecto antecedente en la ilustración del calendario de Philocalus (imagen de Constancio II con toga picta, cetro, y sentado en la sella curulis ${ }^{57}$ ) que es, en mi opinión, el antecedente preciso de la composición que aparece en el missorium de Teodosio I del año 388. La importancia de las monedas o del arte desplegado por los argentarii es aquí fundamental, porque estos objetos de largitiones emergían directamente de las officinae destinadas precisamente a la producción de los mismos ${ }^{58}$.

J. Meischner considera que el escenario arquitectónico que enmarca la escena del missorium toma ejemplo y modelo del propylon de la iglesia de Hagia Sophia, construida por Teodosio II ca. 415, cuyos restos y decoración arquitectónica han servido para una acertada reconstrucción ${ }^{59}$. La autora considera que en Rávena se conocía este edificio y que la escena (aunque simbólica) representaría al emperador en su propio escenario ${ }^{60}$.

Esta interpretación no resulta convincente porque hay que señalar en primer lugar que la escena de investidura de un dignatario o de un emperador no se hace delante de una iglesia. En segundo lugar, hay que decir que el uso de este tipo de arquitectura se detecta ya desde el conjunto arquitectónico de Diocleciano en Espalato hasta el tretrapylon de

${ }^{55}$ Cfr. J. Cl. Golvin, M. Reddé, El-Sayed Hejazy, G. Wagner, Le camp romain de Louqsor, IFAO, Cairo, 1986, con DOP, 29, 1975, p. 225-251 y J. Deckers, JdAI, 94, 1979, p. $600-652$.

${ }_{56} \mathrm{Cfr}$. J. Arce, Estudios sobre el Emperador Fl. Cl. Juliano, Madrid, CSIC; 1984, p. 193 ss. (solidi de Antioquía del 363).

57 Stern (cit. n. 12); Salzman, On Roman Time, p. 34.

${ }^{58}$ P. Bastien (cit. n. 1) p. 29 (con n. 6); Delmaire (cit. n. 1).

${ }_{59}$ A. Schneider, Die Hagia Sophia, 1939, (citado en J.

Meischner, Das Missorium, p. 430, con Abb. 29).

(6) J.M., Missorium, p. 430-431. 
Afrodisias, de época teodosiana, como indica la correspondiente inscripción y se puede hallar también en la propia Tesalónica. Sobre el escenario en el que se enmarca la representación (que habla más a favor de una producción del missorium en la Pars Orientis precisamente por el uso familiarizado de esta forma arquitectónica) quiero solamente recordar lo que escribí hace años y a ello me remito ${ }^{61}$.

Otro punto débil de la propuesta es la interpretación misma de la escena, en la que, según J. Meischner, el emperador Teodosio está confirmando póstumamente a Constancio III como augusto. Ciertamente, no creo que se encuentre ningún ejemplo iconográfico en el que el acto de elevación a augusto se haga mediante la entrega de un codicillum ${ }^{62}$.

Una última cuestión: ¿qué hace el missorium de Teodosio II en las cercanías de Emerita?, ¿cómo ha llegado hasta aquí?, ¿quién era su destinatario?, ¿por qué apareció junto a dos vasa (argentea) hoy desaparecidos pero que Delgado describe en su primera memoria?

La señora Meischner dice expresamente que el missorium fue enviado, en varias copias, a los funcionarios del Imperio, además de al propio Teodosio II a fin de dar a conocer a todos las reclamaciones de Gala Placidia.

Primer obstáculo: los missoria de esta importancia y relieve, por lo que sabemos, no se producían en serie, sino que eran objetos individualizados y precisamente destinados a personajes concretos para ocasiones también concretas. Un missorium no es una imago, ni un eikon: las imagines sí que se enviaban y distribuían como hemos visto que atestigua el mismo Olympiodoro para Constancio III. La razón es muy simple: la imago es una reproducción fiel del individuo, da a conocer su identidad; el missorium representa sin demasiadas precisiones un conjunto simbólico, cuyos rasgos ya se conocen o son familiares al recipiendiario (por ello, la búsqueda de paralelos entre los «retratos» del missorium y otros bustos o retratos en mármol resulta siempre aleatoria y subjetiva).

Pero volvamos a la Diocesis Hispaniarum ${ }^{63}$. La situación política de los años que van desde el 409 al 421 en la Península no puede ser más caótica y desfavorable para Honorio, y es ciertamente el mo-

${ }^{61}$ J. Arce (cit. n. 1) p. 130-132.

62 J. Arce ibm. p. 122-128; Kiilerich (cit. n. 1) p. 22 con la discusión; Bastien (cit. n. 1) p. 29, n. 6; sobre el nimbus que aparece ya en el s. II en la iconografía imperial: Kiilerich (cit. n. 1) p. 23, n. 58, con la discusión.

${ }^{6.3}$ Sobre esto ver J. Arce, Comunicación, ejército y moneda en Hispania (s. IV-V d. C.), en prensa en Actas del II EPNA, Anejos de AEspA; P. S. Barnwell, Emperors, Prefects and Kings, Duckworth, London, 1992, p. 71-82. mento menos apropiado para poder hablar de gobernadores romanos legítimamente establecidos en las provincias hispánicas, cuando incluso ya ni existían, y Augusta Emerita había dejado de ser la capital administrativa simplemente porque el control romano había desaparecido y estaba en manos de pueblos bárbaros fragmentados y diseminados por el territorio con sus propios reges, que no estaban en absoluto en la Península en un régimen de foedus con Roma.

La crónica de Hydacio recuerda monótonamente los intentos de recuperación por parte de ejércitos romanos del territorio peninsular, en el año 417, en el 418 y en el 419. Para el 420 la crónica gálica registra una nueva usurpación en Hispania, la de Máximo, por segunda vez. Esta usurpación duró al menos dos años y hasta el 422 no fue sofocada. En este período de inseguridad y anarquía nos gustaría saber cómo continuó y se desarrolló la administración romana en la Península. Nuestro vacío informativo es casi total y, aunque conocemos acciones puntuales y personajes que son enviados revestidos con el título de comites Hispaniarum (el caso de Maurocellus, vicarius, al mando de las tropas en Gallaecia, es uno de ellos), la realidad es que Honorio no controlaba las provincias hispánicas en estas fechas excepto, en todo caso, alguna parte de la Tarraconense ${ }^{64}$.

En estas circunstancias el missorium propagandístico enviado a Emerita no tiene ni sentido ni explicación, porque la diocesis escapaba al control romano del emperador occidental. Claro es que siempre se puede argüir que el missorium fue transportado posteriormente por su propietario cuando eventualmente éste se hubiese trasladado a Hispania en un momento desconocido. Pero la historia no se puede hacer con suposiciones.

Los dos vasos que acompañaban el missorium parecen significar que el conjunto era un regalo en el que éste no estaba solo. Ellos aumentan la certeza de que se trata de una donación que, como era frecuente, demostraba la largitio imperial hacia su funcionario fiel y a quien se investía de la alta responsabilidad del gobierno provincial.

\section{CONCLusión}

La conclusión me parece evidente: la explicación de que en el missorium está representado Teodosio II, como se ha propuesto recientemente, obliga a realizar una serie de suposiciones sin clara y sólida

\footnotetext{
${ }_{64}$ Maurocellus, PLRE, II s.v.; P. Barnwell, ibm.
} 
fundamentación en la documentación antigua. Supone forzar los datos e imaginar lo que pudo haber sucedido sin que sepamos qué sucedió de hecho, en vez de dar una explicación lineal y clara, razonada y acorde con la documentación disponible (como ocurre, sin embargo, cuando nos referimos al missorium como obra de Teodosio I); y propone una explicación indemostrable en la que los distintos elementos no se ajustan coherentemente. Presenta, del mismo modo, dificultades insalvables: celebraría unas decennalia para Teodosio II, cuatro o diez años después de que las hubiese celebrado de hecho, como relatan las crónicas. Pretender que se celebraran otra vez, es simplemente inaceptable.

La tradición artística a la que pertenece el missorium, sus modelos iconográficos, sus elementos estilísticos, se remontan al menos a comienzos del s. IV d. C. en sus esquemas esenciales. Y los rasgos estilísticos pertenecen de lleno al arte de la época teodosiana (último cuarto del siglo) aunque los paralelismos que se puedan presentar se hallen diseminados en un amplio período cronológico. El missorium es obra de artífices que pretendieron más ofrecer la impresión de conjunto que la identificación de los detalles fisionómicos precisos. Y corremos el riesgo de intentar fechar estilísticamente utilizando objetos o paralelos que, a su vez, no están tampoco definitivamente ni rigurosamente fechados, ya que se hallan sometidos ellos mismos a grandes fluctuaciones de cronología y de identificación (un ejemplo sería el famoso «Arcadio» de Constantinopla).

Por todo lo dicho, creo que podemos seguir sin problemas pensando que Teodosio I sigue siendo Teodosio I en el missorium de Madrid ${ }^{65}$.

\section{ADDENDUM}

J. Meischner menciona y aduce una serie de leyes del Código Teodosiano (p. 419, n. 75) que parecen indicar que se siguió legislando en nombre de Constancio III con carácter póstumo, lo que signifi-

${ }^{65}$ El peso del missorium expresado en griego en el anverso del mismo, significa que el objeto no fue producido en Occidente; Kiilerich (cit. n. 1) p. 26. caría, según ella, un reconocimiento de su nombramiento por parte de Teodosio II después de su muerte, corroborando así la interpretación de la escena del missorium. Sin embargo, este argumento es insuficiente y erróneo. Debo agradecer a Geoffrey Lambert, del Departamento de Historia Medieval de la Universidad de Leeds y que realiza un estudio extenso sobre el emperador Teodosio II, el haber proporcionado la siguiente respuesta a mis preguntas sobre este tema, que yo reproduzco en forma abreviada:

«CTh 2.27.1 (Rávena, Julio 28 del 421: Honorio, Teodosio, Constancio). According to my source therefore this law was issued within Constantius' period in "office" (Fab. 421-Sept. 421). It also reflects that Honorius was the most senior Augustus and farther suggests that he recognised Constantius as a co-regent.

CTh. 3.16.2: issued at Rávena, March 10, 421 by Honorius, Theodosius and Constantius. Same observations-coments as above.

CTh. 10.19.29 (Meischner, n. 75): this reference seems erroneous... I can not locate a law with such a reference.

CTh. 10.10.30: issued at Rávena Jul. 8, 421, Honorius, Theodosius and Constantius. Same observation as above.

CTh. 10.10.31: posted in the Forum of Trajan, August, 25 of 422 by Honorius, Theodosius and Constantius. This law falls outside/after Constantius period in office. I believe it has most likely been incorrectly ascribed. In respect of this, I note that Laws 8.8.10 and 11.28.13 were issued at Rávena, similarly in a. d. 422 and also in the year of 13th consulship of Honorius and 10th of Theodosius, but did not include Constantius name».

Estas observaciones invalidan la argumentación de J. Meischner sobre el reconocimiento póstumo de Constancio III. G. Lambert añadía los siguientes comentarios a mis consultas: «there is also however no indication as to the possible role of Placidia in securing his elevation, even after entering a marriage she did not want. I believe such an attitude was most susceptible to change and the pragmatic political oportunities available, especially with the birth of Valentinian, a potential future emperor and source of continued power for Placidia». 